\title{
Awareness among nurses about reporting of adverse drug reactions in Sweden
}

This article was published in the following Dove Press journal:

Drug, Healthcare and Patient Safety

27 June 2012

Number of times this article has been viewed

\author{
Elisabet Ekman ${ }^{1-3}$ \\ Göran Petersson ${ }^{2}$ \\ Sven Tågerud ${ }^{3}$ \\ Martin Bäckström ${ }^{4}$ \\ 'Regional Pharmacovigilance Unit, \\ R \& D Centre Skåne, Skåne University \\ Hospital, Lund, ${ }^{2}$ eHealth Institute, \\ Linnaeus University, Kalmar, ${ }^{3}$ School of \\ Natural Sciences, Linnaeus University, \\ Kalmar, ${ }^{4}$ Regional Pharmacovigilance \\ Unit, Division of Clinical \\ Pharmacology, University Hospital of \\ Umeå, Umeå, Sweden
}

Background: The purpose of this study was to investigate awareness among nurses regarding their new role as reporters of adverse drug reactions in Sweden and factors that may influence reporting by nurses.

Methods: In 2007, all nurses were included in the adverse drug reaction reporting scheme in Sweden. A questionnaire was sent to 753 randomly selected nurses in September 2010.

Results: Of the 453 (60\%) responding nurses, 265 (58\%) were aware that nurses were included in the reporting of adverse drug reactions. Sixty-one nurses (14\%) stated that they had reported an adverse drug reaction. Fifteen percent $(n=70)$ of the respondents had received training about reporting of adverse drug reactions. Almost one third of these $(n=21,30 \%)$ had reported an adverse drug reaction on at least one occasion. Among nurses without training, a smaller proportion $(\mathrm{n}=40,11 \%, P<0.05)$ had reported an adverse drug reaction on at least one occasion. The two factors considered most important by nurses for reporting were the severity of the adverse drug reaction and if the reaction was to a newly approved drug. A majority of the nurses $(n=397,88 \%)$ were interested in a training course in pharmacology as part of their ongoing professional development. One third (32\%) of all nurses stated that one reason for not reporting a suspected adverse drug reaction was that the physician responsible did not regard the reaction necessary to report.

Conclusion: We found that more than half of the study population of nurses in Sweden were aware of their new role as reporters of adverse drug reactions, but few of the responding nurses had reported an adverse drug reaction. Given that training seems to be associated with high reporting frequency, we suggest more training in pharmacovigilance for nurses.

Keywords: adverse drug reporting systems, nurses, knowledge

\section{Introduction}

Adverse drug reactions (ADRs) are common causes of hospitalization and death. ${ }^{1,2}$ Spontaneous reporting of ADRs is one of the basic methods for post-marketing surveillance and constitutes one of the most important cornerstones for detection of signals indicating new and serious ADRs. Withdrawals due to safety problems are often based on data from spontaneous reporting systems. ${ }^{3}$ Underreporting is one of the major limitations of spontaneous reporting. ${ }^{4}$ From an international perspective, reporting of ADRs in Sweden (population 9.4 million) has traditionally been high. In 2004, the reporting rate in Sweden was 465 reports per million inhabitants, the highest reporting rate in the European Economic Community, according to the Assessment of the European Community System of Pharmacovigilance (final report January 25, 2006). In 2009, the reporting rate was 629 per million inhabitants. However, we know that there is also considerable underreporting in Sweden. ${ }^{5,6}$
Correspondence: Elisabet Ekman Regional Pharmacovigilance Unit, R \& D Centre Skåne, Skåne University Hospital, SE 22185 Lund, Sweden Tel +46 46I7 5338

Email elisabet.ekman@med.lu.se 
According to the code of statutes of the Swedish Medical Products Agency, it is mandatory for health care professionals to report serious drug reactions, new and unexpected reactions, and also those reactions that seem to increase in frequency. For new drugs, reporting of all adverse effects, except those labeled as common in the Summary of Product Characteristics, is encouraged. An ADR is defined as a response that is noxious and unintended, and that occurs at doses normally used in humans for the prophylaxis, diagnosis, or treatment of disease, or for the modification of physiological function. ${ }^{7} \mathrm{~A}$ serious ADR is any untoward medical occurrence that at any dose results in death, is life-threatening, requires inpatient hospitalization or prolongation of existing hospitalization, results in persistent or significant disability/incapacity, or is a congenital anomaly/birth defect.

ADR reports in Sweden are handled at regional pharmacovigilance centers, situated at six university hospitals, by an expert panel consisting of clinical pharmacologists and specially trained nurses and pharmacists. Each individual report is stored in the national Swedish Drug Information System database.

According to data from the National Board of Health and Welfare in Sweden, nurses form the largest group of health professionals, numbering approximately 137,000, compared with approximately 40,000 doctors. Studies from European countries have described nurses as reporters, ${ }^{8,9}$ and two Swedish studies have shown that hospital nurses can contribute to the reporting of ADRs. ${ }^{10,11}$ Furthermore, an official report initiated by the Medical Products Agency, with a focus on pharmacovigilance in Sweden, has suggested that all nurses should be included in the reporting scheme. ${ }^{12}$ Consequently, the Medical Products Agency decided to include all nurses in the reporting scheme in April 2007. Before April 2007, the Medical Products Agency defined health care professionals as physicians, dentists, prescribing nurses, and nurses working in child and school health care. Pharmacists have not yet been included in the pharmacovigilance system in Sweden.

The aim of this study was to investigate awareness among nurses regarding their new role as reporters of ADRs in Sweden and factors that may influence reporting by nurses.

\section{Materials and methods Study design and population}

Data from a postal questionnaire investigating nurses' knowledge of, attitudes to, and motives for reporting of ADRs was used. The questionnaire was sent to 753 randomly selected nurses. The nurses were selected from the 75,300 nurses who are members of the Swedish Association of Health
Professionals. Every hundredth nurse was selected from an alphabetical list of the membership register (Figure 1).

\section{Questionnaire}

The questionnaire comprised four parts: demographic data (age, sex, years in profession, working with outpatients, and hospital care); general questions about knowledge of pharmacology, ADR reporting, and factors relevant for the decision to report or refrain from reporting; suggestions to improve reporting, such as electronic reporting directly via the patient's medical record using a simplified form, reporting without a form, reporting by phone; and interest in receiving feedback with information about the causality assessment. The answers were graded as "important/yes", "neither/nor (neutral)", or "unimportant/no". At the end of the questionnaire, there was a free text area for comments.

A pilot study of the questionnaire was performed using 30 clinically active nurses, without any need for adjustments.

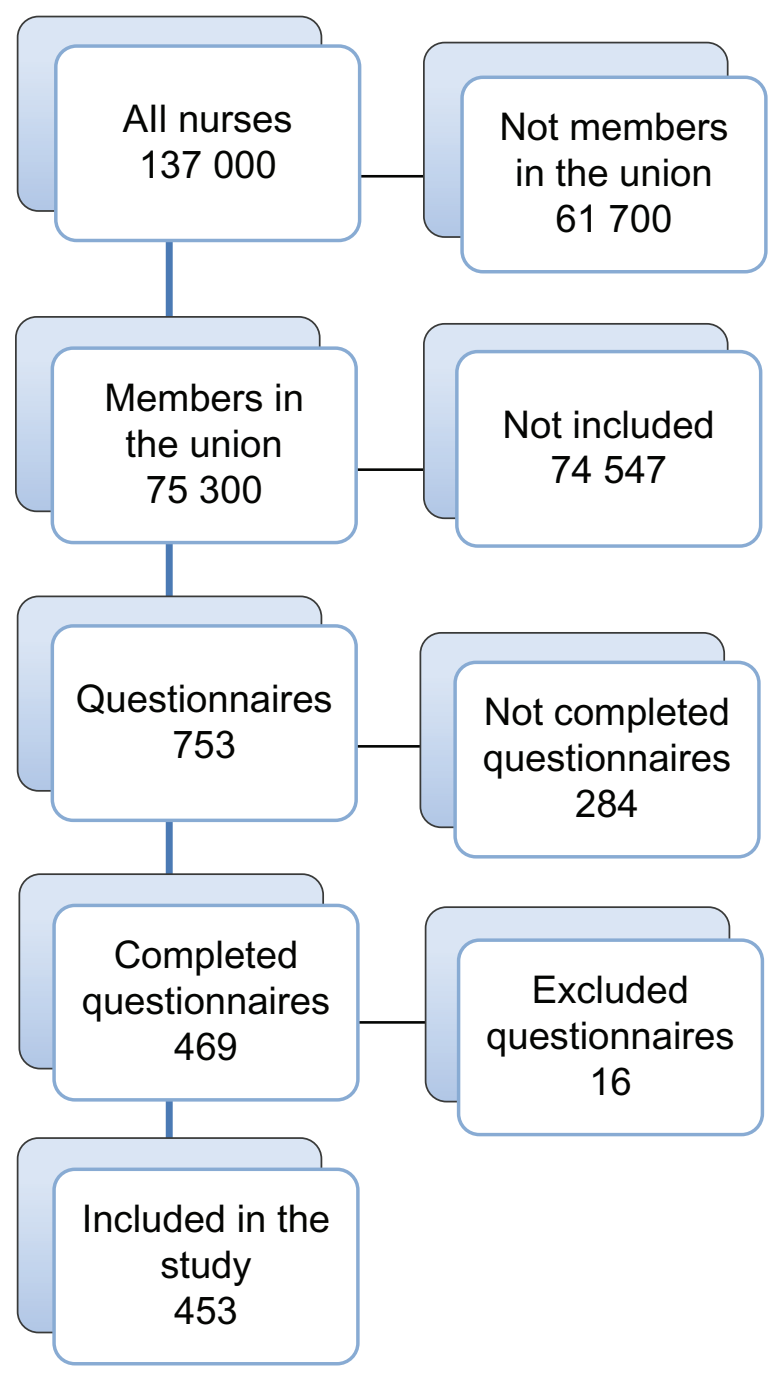

Figure I Flow chart describing the selection process for the included nurses. 
An almost identical questionnaire has been used in other studies investigating physicians and nurses attitudes to reporting. ${ }^{11,13,14}$ The questionnaire was sent by mail in September 2010 with a reminder two weeks later. Because the questionnaire was answered anonymously, the reminder was sent to all recipients.

\section{Statistical analysis}

The SPSS Statistics software (version 18; SPSS Inc, Chicago, IL) was used for the statistical analysis. Chi-square testing was used to identify any significant differences. For reporting of ADRs, a comparison was made between nurses with and without training in pharmacovigilance. Other comparisons were made between nurses with 20 years or less in their profession and colleagues with 21 years or more in the profession. A $P$ value $<0.05$ was considered statistically significant.

\section{Results \\ Questionnaires}

Of the 753 questionnaires distributed, 453 were completed, giving a total response rate of $60 \%$. Twelve of the distributed questionnaires were excluded because they were inadequately filled in, three were returned due to unknown addresses, and one was excluded due to late arrival (Figure 1). Missing data (internal loss) for the different questions ranged from $12 \%$ to $17 \%$.

\section{Demographic data}

Of the respondents, 46 (10\%) were male, 405 (89\%) were female, and two did not report their sex. Four hundred seven $(90 \%)$ of the respondents stated the number of years in their profession. On average, the respondents had worked for 18 (range 1-44) years in their profession, and their mean age was 45 (range 21-66) years. About half of the respondents worked in outpatient care, almost $40 \%$ worked in hospitals, and $13 \%$ worked elsewhere or did not specify their employment (Table 1).

\section{Knowledge and training}

About one third of the nurses $(n=164,36 \%)$ stated that they had sufficient knowledge of pharmacology in general. A majority $(n=397,88 \%)$ were interested in a training course in pharmacology as part of their ongoing professional development. More than half of the respondents $(n=265$, $58 \%$ ) were aware that nurses were included in the reporting of ADRs. Seventy (15\%) had received some kind of training about how and when to report a suspected ADR.

\section{Reporting of ADRs}

Of the responding nurses, 61 (14\%) stated that they had reported an ADR on at least one occasion (Table 2). Among nurses who had received training about reporting of ADRs, almost one third $(\mathrm{n}=21,30 \%)$ had reported an ADR on at least one occasion. Among the nurses who had not received training about reporting of ADRs, a smaller proportion (n $=40,11 \%, P<0.05)$ had reported an ADR on at least one occasion. Almost all $(n=446,98 \%)$ considered that nurses could contribute to the reporting of ADRs.

The two factors considered most important by nurses for reporting ADRs were the severity of the ADR and if the reaction was to a newly approved drug. For nurses with 21 years or more in their profession, an unusual reaction was considered more important $(P<0.05)$ for determining whether or not to report an ADR (Table 3). Nurses with a shorter time in the profession responded to a higher degree $(P<0.05)$ than their senior colleagues that they were uncertain how to report, unaware of what to report, that they had difficulty in finding the right form, or had no time to report. One third $(32 \%)$ of all nurses stated that one reason for not reporting a suspected ADR was that the physician responsible did not regard the reaction necessary to report (Table 4), and 12\%

Table I Description of responders

\begin{tabular}{|c|c|c|c|c|c|c|c|c|}
\hline & \multicolumn{2}{|c|}{ All responders } & \multirow{2}{*}{\multicolumn{2}{|c|}{$\begin{array}{l}\text { Education } \\
\text { in reporting }\end{array}$}} & \multicolumn{4}{|c|}{ Years in profession* } \\
\hline & \multirow[t]{2}{*}{ n } & \multirow[t]{2}{*}{$\%$} & & & \multicolumn{2}{|c|}{$1-20$} & \multicolumn{2}{|c|}{$2 I-44$} \\
\hline & & & $\mathbf{n}$ & $\%$ & $\mathbf{n}$ & $\%$ & $\mathbf{n}$ & $\%$ \\
\hline Female & 405 & 89 & 63 & 14 & 210 & 46 & 156 & 34 \\
\hline Male & 46 & 10 & 7 & 15 & 29 & 7 & 12 & 3 \\
\hline Sex not stated & 2 & $\mathrm{I}$ & & & & & & \\
\hline Total & 453 & 100 & 70 & 15 & 239 & 53 & 168 & 37 \\
\hline Outpatient care & 220 & 49 & 42 & 19 & 67 & 15 & 85 & 19 \\
\hline Hospital nurses & 172 & 38 & 16 & 9 & 144 & 32 & 56 & 13 \\
\hline Other employment or not stated & 61 & 13 & 12 & 20 & 28 & 6 & 27 & 6 \\
\hline
\end{tabular}

Note: *Respondents not stating years in profession or place of work excluded from these groups. 
Table 2 Reporting of ADRs in relation to training about reporting

\begin{tabular}{llll}
\hline & $\begin{array}{l}\text { Training } \\
\text { in reporting } \\
\mathbf{n}(\%)\end{array}$ & $\begin{array}{l}\text { No training } \\
\text { in reporting } \\
\mathbf{n}(\%)\end{array}$ & $\begin{array}{l}\text { Total } \\
\mathbf{n}(\%)\end{array}$ \\
\hline Reported ADRs & $21(30)$ & $40(11)$ & $61(14)$ \\
No reported ADRs & $49(70)$ & $336(89)$ & $384(86)$ \\
Total & $70(100)$ & $376(100)$ & $446(100)$ \\
\hline
\end{tabular}

Note: $P<0.05$.

Abbreviation: ADRs, adverse drug reactions.

considered that physicians disapproved of nurses as reporters, without any difference $(P>0.05)$ between nurses with shorter or longer experience.

Three hundred twenty-two (71\%) nurses stated that following reporting of an ADR they would like a feedback letter from their regional pharmacovigilance center containing an assessment of causality. A majority $(n=380,84 \%)$ considered that reporting a suspected ADR using a Web-based system would facilitate reporting. One hundred ninety-three respondents (43\%) expressed a desire to have a simplified report form, and $53(12 \%)$ stated that submission of notes from patient medical records, without a separate reporting form, would facilitate reporting.

\section{Free text area}

Forty-seven (10\%) of the respondents had used the free text area. A majority commented that nurses are not aware of the reporting of ADRs per se and its importance. Six nurses stated that they did not work clinically, and four considered that reporting should be done by physicians.

\section{Discussion}

We found that more than half of the responding nurses were aware of their new role as reporters of ADRs. The main reason for the Swedish authorities including nurses as reporters of ADRs was to broaden the group of reporters with a subsequent increase in the reporting rate and a general increase in awareness of the problem with ADRs. However, three years after the introduction of nurses as reporters of suspected ADRs, this reform has not had any major impact on the reporting rate in Sweden. ${ }^{15}$ One explanation for this could be limited awareness on the part of nurses concerning their new professional role. Another explanation for the low reporting rate could be that nurses in general believe that they have inadequate knowledge of pharmacology and insufficient basic knowledge to identify an ADR. Nearly $90 \%$ of respondents stated that they would be interested in a training course in pharmacology as part of their ongoing professional development. Furthermore, more than $10 \%$ of the nurses stated that they regarded physicians as having a negative attitude towards nurses as reporters of ADRs. There seems to be some support for this view, because another study has shown that $30 \%$ of hospital physicians disapproved of nurses as reporters, and younger physicians were reported to be more negative than their older colleagues. ${ }^{13}$

\section{Professional experience}

We found that nurses with more professional experience were more familiar with the existing reporting regulations than those with limited experience. Nurses with less professional experience responded to a greater extent that they did not have the time to report and had other priorities. Moreover, they were more uncertain as to how and what to report, and also had difficulty in finding the correct form for reporting. It is likely that nurses with a longer experience are more independent and have sufficient self-confidence to make this decision by themselves, a finding which is in line with that of McGettigan et al, who reported that seniority increased the likelihood of reporting ADRs among hospital physicians. ${ }^{16}$ Another explanation for why nurses with more experience responded that they were more familiar with the reporting rules might be that they had prior reporting experience. However, this is not likely, because nurses had only been involved in the reporting scheme for 3.5 years at the time of the study.

Table 3 Factors important in determining whether or not to report a suspected adverse drug reaction according to years in profession

\begin{tabular}{|c|c|c|c|c|c|c|c|}
\hline & \multicolumn{4}{|c|}{ Years in profession } & \multicolumn{2}{|l|}{ Total } & \multirow[t]{3}{*}{$P$ value } \\
\hline & \multicolumn{2}{|l|}{$1-20$} & \multicolumn{2}{|l|}{$21-44$} & \multirow[t]{2}{*}{$n=407 * *$} & \multirow[t]{2}{*}{$\%$} & \\
\hline & $n=239$ & $\%$ & $n=168$ & $\%$ & & & \\
\hline Severity of reaction & 216 & 90 & 156 & 93 & 372 & 91 & 0.380 \\
\hline Reaction to a newly approved drug & 218 & 91 & 152 & 90 & 370 & 91 & 0.465 \\
\hline Unusual reaction & 173 & 72 & 135 & 80 & 308 & 76 & $0.04 I^{*}$ \\
\hline Unlabeled reaction & 158 & 66 & 106 & 63 & 264 & 65 & 0.531 \\
\hline Certainty that reaction was due to an ADR & 125 & 52 & 105 & 63 & 230 & 56 & $0.04 I^{*}$ \\
\hline
\end{tabular}

Notes: $* P$ value $<0.05$; **respondents who did not state years in profession were excluded from analysis. 
Table 4 Factors important for refraining from reporting an adverse drug reaction according to years in profession

\begin{tabular}{|c|c|c|c|c|c|c|c|}
\hline & \multicolumn{4}{|c|}{ Years in profession } & \multicolumn{2}{|l|}{ Total } & \multirow[t]{3}{*}{$P$ value } \\
\hline & \multicolumn{2}{|l|}{$1-20$} & \multicolumn{2}{|l|}{$21-44$} & \multirow[t]{2}{*}{$n=407 * *$} & \multirow[t]{2}{*}{$\%$} & \\
\hline & $n=239$ & $\%$ & $n=168$ & $\%$ & & & \\
\hline Reaction well known & 137 & 57 & 90 & 53 & 227 & 56 & 0.056 \\
\hline Uncertain how to report & 138 & 58 & 70 & $4 I$ & 208 & 51 & $0.001 *$ \\
\hline Unaware what to report & 120 & 50 & 53 & 31 & 173 & 42 & $0.00 I^{*}$ \\
\hline Difficulty in finding the correct form & 107 & 45 & 52 & 31 & 159 & 39 & $0.005^{*}$ \\
\hline Difficulties in reporting only on suspicion & 97 & 40 & 54 & 32 & $15 \mid$ & 37 & 0.08 \\
\hline Physician sees no need to report & 84 & 35 & 48 & 28 & 132 & 32 & 0.16 \\
\hline No time to report & 88 & 37 & 33 & 20 & $12 \mid$ & 30 & $0.001 *$ \\
\hline Forgetfulness & 50 & 21 & 22 & 13 & 72 & 18 & $0.004 *$ \\
\hline Making other priorities & 50 & 21 & 17 & 10 & 67 & 16 & $0.004^{*}$ \\
\hline
\end{tabular}

Notes: $* P$ value $<0.05$. **respondents who did not state years in profession were excluded from analysis.

\section{Reporting methods}

A majority stated that being able report ADRs using a Webbased form would be an important tool for improving the overall reporting rate, in line with a previous study. ${ }^{13}$ Thus, in order to improve the reporting rate, creation of a Web-based form seems to be an important task for the Medical Products Agency in Sweden.

\section{Ongoing professional development}

It seems reasonable that an opportunity for nurses to refresh their knowledge of pharmacology should be provided. It is of concern that up to two thirds of the responding nurses considered that they did not have sufficient knowledge of pharmacology. In 2006, individuals in Sweden received on average 4.7 dispensed drugs, and almost $25 \%$ of the population had five or more drugs dispensed. For individuals over 70 years of age, the mean number of dispensed drugs was 7.9. ${ }^{17}$ Thus, health care is a drug-intensive activity, and an adequate knowledge of pharmacology could be regarded as essential for nurses.

Before 2007, nurses in Sweden had not received any training at all in pharmacovigilance (personal communication, Kerstin Jorsäter-Blomgren, Mälardalen University, Sweden). Therefore, knowledge about reporting of ADRs among professional nurses is likely to be low. Extrapolating from the number of respondents who had received some training in how and when to report ( $\mathrm{n}=70,15 \%$ in the present study), this would mean that, in total, about 20,000 nurses in Sweden have received such training. This figure seems reasonable, because the regional pharmacovigilance centers in Sweden have provided courses on many occasions to nurses or to nursing students for many years. Among the respondents who had received training, almost one third reported ADRs compared with $11 \%$ in the group that had not received any training. This finding suggests that training is required to improve reporting, and also suggests that it takes a long time to introduce a new category of reporters, which is a finding confirmed among hospital pharmacists. ${ }^{18}$ In contrast with other countries, pharmacists in Sweden are not yet included as reporters of ADRs. When included, pharmacists might improve the reporting rate even more.

\section{Representativeness of study population}

We obtained addresses for the selected nurses through their trade union, ie, the Swedish Association of Health Professionals. There are some limitations with this approach, because we have no information regarding nurses who are not members of the union. However, this was the only way to get access to an address register for nurses in Sweden, and the overall membership is high, including at least $50 \%$ of nurses in Sweden.

The response rate to the questionnaire was reasonable, and somewhat higher than that reported by other studies conducted in Sweden. ${ }^{13,14}$ However, we do not have any information from the $40 \%$ of nurses that did not respond to the questionnaire. One could assume that the nurses who responded are interested in ADRs to a higher degree and have a greater awareness about reporting than the nurses who did not respond. Trade union membership may also have influenced the results, eg, members might have better awareness of ADR reporting than nonmembers. Furthermore, missing information from the respondents might have affected the study data and contributed to overestimation of the results. A pilot study was performed among clinically active nurses. In the final population that responded to the questionnaire, $13 \%$ (Table 1) either did not state their employment or were active in positions other than hospitals or outpatient care, so a proportion of respondents 
may have found some questions irrelevant in relation to their present duties.

\section{Conclusion}

We found that more than half of the nurses in the Swedish study population were aware of their new role as reporters of ADRs, but only few of the responding nurses had reported an ADR. Given that training seems associated with a high reporting frequency, we suggest more training in pharmacovigilance for nurses.

\section{Acknowledgment}

We express our appreciation to the Swedish Association of Health Professionals in Sweden. Without their support, interest, and willingness to help us with the selection from their member registry, this study would not have been possible. We also thank Anders Sundström for help with the statistical analysis.

\section{Disclosure}

The authors report no conflicts of interest in this work.

\section{References}

1. Mjörndal T, Boman MD, Hägg S, et al. Adverse drug reactions as a cause for admissions to a department of internal medicine. Pharmacoepidemiol Drug Saf. 2002;11(1):65-72.

2. Wester K, Jonsson AK, Spigset O, Druid H, Hagg S. Incidence of fatal adverse drug reactions: a population based study. Br J Clin Pharmacol. 2008;65(4):573-579.

3. Olivier P, Montastruc JL. The nature of the scientific evidence leading to drug withdrawals for pharmacovigilance reasons in France. Pharmacoepidemiol Drug Saf. 2006;15(11):808-882.

4. Hazell L, Shakir SA. Under-reporting of adverse drug reactions: a systematic review. Drug Saf. 2006;29(5):385-396.
5. Bäckström M, Mjörndal T, Dahlqvist R. Under-reporting of serious adverse drug reactions in Sweden. Pharmacoepidemiol Drug Saf. 2004;13(7):483-487.

6. Samuelsson E, Hägg S, Bäckström M, Granberg K, Mjörndal T. Thrombosis caused by oral contraceptives. Underreporting to the adverse effects registry. Läkartidningen. 1996;93(37):3117-3118. Swedish.

7. Lindquist M. The need for definitions in pharmacovigilance. Drug Saf. 2007;30(10):825-830.

8. Morrison-Griffiths S, Walley TJ, Park BK, Breckenridge AM, Pirmohamed M. Reporting of adverse drug reactions by nurses. Lancet. 2003;361(9366):1347-1348.

9. Morrison-Griffiths S, Pirmohamed M. Specialist nurse reporting of adverse drug reactions. Prof Nurse. 2000;15(5):300-304.

10. Bäckström M, Mjörndal T, Dahlqvist R. Spontaneous reporting of adverse drug reactions by nurses. Pharmacoepidemiol Drug Saf. 2002;11(8):647-650.

11. Bäckström M, Ekman E, Mjörndal T. Adverse drug reaction reporting by nurses in Sweden. Eur J Clin Pharmacol. 2007;63(6):613-618.

12. Investigation of adverse reaction reporting. Medical Product Agency; [cited March 15 2009]. Available from: http://www.lakemedelsverket. se/upload/om-lakemedelsverket/publikationer/Biverkningsrelaterat/ biverkningsutredningen_0512.pdf. Accessed September 15, 2011. [Swedish].

13. Ekman E, Backstrom M. Attitudes among hospital physicians to the reporting of adverse drug reactions in Sweden. Eur J Clin Pharmacol. 2009;65(1):43-46.

14. Bäckström M, Mjörndal T, Dahlqvist R, Nordkvist-Olsson T. Attitudes to reporting adverse drug reactions in northern Sweden. Eur J Clin Pharmacol. 2000;56(9-10):729-732.

15. Reported adverse reactions from health care 2010. Medical Product Agency; [cited April 19 2011]. Available from: http://www.lakemedelsverket.se/Alla-nyheter/NYHETER-2011/Halso-och-sjukvardensinrapporterade-biverkningar-2010/. Accessed September 15, 2011. [Swedish].

16. McGettigan P, Golden J, Conroy RM, Arthur N, Feely J. Reporting of adverse drug reactions by hospital doctors and the response to intervention. Br J Clin Pharmacol. 1997;44(1):98-100.

17. Hovstadius B, Astrand B, Petersson G. Dispensed drugs and multiple medications in the Swedish population: an individual-based register study. BMC Clin Pharmacol. 2009;9:11.

18. Green CF, Mottram DR, Rowe PH, Pirmohamed M. Attitudes and knowledge of hospital pharmacists to adverse drug reaction reporting. Br J Clin Pharmacol. 2001;51(1):81-86.
Drug, Healthcare and Patient Safety

\section{Publish your work in this journal}

Drug, Healthcare and Patient Safety is an international, peer-reviewed open-access journal exploring patient safety issues in the healthcare continuum from diagnostic and screening interventions through to treatment, drug therapy and surgery. The journal is characterized by the rapid reporting of reviews, original research, clinical, epidemiological and

\section{Dovepress}

post-marketing surveillance studies, risk management, health literacy and educational programs across all areas of healthcare delivery. The manuscript management system is completely online and includes a very quick and fair peer-review system. Visit http://www.dovepress.com/ testimonials.php to read real quotes from published authors. 